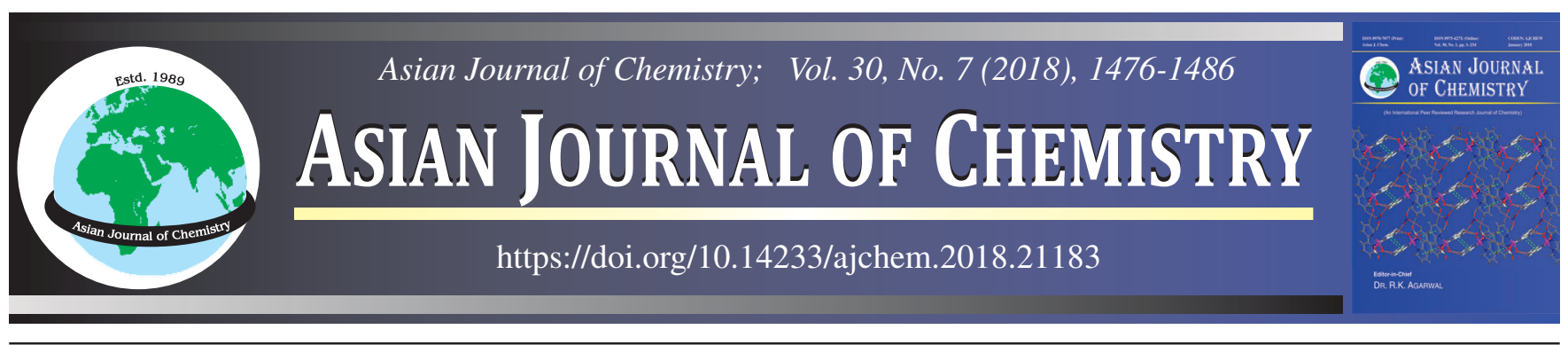

\title{
Density Functional Studies of Electronic Structure, Chemical Bonding and Thermodynamic Properties of Ternary Lanthanum-Gold-Cadmium Inorganic Materials
}

\author{
Jyoti SAGAR* and ReEtu Singh
}

Department of Chemistry, S.S.V. Post Graduate College, Hapur-245 101, India

*Corresponding author: E-mail: jyotisagar20@gmail.com

Received: 14 December 2017;

Accepted: 13 April 2018;

Published online: 31 May 2018;

AJC-18917

\begin{abstract}
Density functional theory analyses of electronic structure together with thermodynamic properties were performed for the two promising ternary rare earth gold compounds (viz. LaAuCd and $\mathrm{La}_{2} \mathrm{Au}_{2} \mathrm{Cd}$ ). We have applied the state-of-the-art full potential linear augmented plane wave plus local orbital (FP-LAPW + lo) method. Exchange and correlation potential were introduced within the framework of the generalized gradient approximation (GGA). Careful analysis of valance charge density distribution shows ionic character whereas electron dispersion curves indicate that both the compounds possess metallic character. This metallic character in both the compounds is caused by bonding of La-p, Au-p and Cd-p orbitals in terms of hybridization at Fermi level. Effects of temperature and pressure on bulk modulus, Debye temperature, specific heat, thermal expansion coefficient and entropy have been investigated in wide temperature and pressure range. The calculated lattice parameters are in good agreement with available experimental/theoretical literature values. Thermodynamic properties of $\mathrm{LaAuCd}$ and $\mathrm{La}_{2} \mathrm{Au}_{2} \mathrm{Cd}$ have been estimated for the first time and explained on the basic facts.
\end{abstract}

Keywords: Intermetallics, Electronic structure, Thermodynamic properties.

\section{INTRODUCTION}

Material chemistry has always been a growing field in the modern research. For the development of new materials, not only the experimental characterization but also theoretical calculations play an important role. Such methods have been found to predict good values of the properties, which have been confirmed experimentally. Density functional theory (DFT) is one such theoretical approach, which provides an appropriate mathematical framework for determining the ground state properties of the crystalline material systems.

A class of compounds that has attracted a great deal of attention in recent years is known as ternary rare earth transition metal compounds. There are large numbers of ternary rare earth transition metal compounds with 1:1:1 and 2:2:1 stoichiometry viz. $\mathrm{LnAuCd}$ and $\mathrm{Ln}_{2} \mathrm{Au}_{2} \mathrm{Cd}$ ( $\mathrm{Ln}=$ lanthanides) [1]. In the literature, only structural information [2,3] is available about $\mathrm{LnAuCd}$ and $\mathrm{Ln}_{2} \mathrm{Au}_{2} \mathrm{Cd}$ compounds. In these compounds, $f$-orbital electrons of lanthanide and $d$-orbital electrons of $\mathrm{Au}$ and $\mathrm{Cd}$ play an important role in the electronic bonding characterization. Therefore, a special focus has been made on two compounds $\mathrm{LaAuCd}$ and $\mathrm{La}_{2} \mathrm{Au}_{2} \mathrm{Cd}$ of $\mathrm{LnAuCd}$ and $\mathrm{RE}_{2} \mathrm{Au}_{2} \mathrm{Cd}$ series to study the band structure along with the total and partial density of states to know the origin of chemical bonding. From literature's point of view, the new intermetallic lanthanide compounds $\mathrm{LaAuCd}$ and $\mathrm{La}_{2} \mathrm{Au}_{2} \mathrm{Cd}$ were prepared by reaction of the elements in sealed tantalum tubes in a high frequency furnace by Mishra et al. [2]. The compounds were investigated by X-ray diffraction in both the powder and single crystal form. Mishra et al. [2] measured the susceptibility of many similar type compounds and found that $\mathrm{YbAuCd}$ consists of Pauli's paramagnetism while EuAuCd consists of Curie Weiss behaviour above $100 \mathrm{~K}$ with experimental magnetic moment $7.86 \mu_{\mathrm{B}} / \mathrm{Eu}$. The equiatomic compound $\mathrm{LaAuCd}$ adopts the hexagonal $\mathrm{ZrNiAl}$ type structure with space group $\mathrm{P}-62 \mathrm{~m}$, which is a ternary version of $\mathrm{Fe}_{2} \mathrm{P}$ type structure [4,5] and $\mathrm{La}_{2} \mathrm{Au}_{2} \mathrm{Cd}$ compound crystallize with the $\mathrm{Mo}_{2} \mathrm{~B}_{2} \mathrm{Fe}$ structure which is a ternary version of $\mathrm{U}_{3} \mathrm{Si}_{2}$ type structure [6-8].

\section{COMPUTATIONAL METHODS}

The structural properties have been performed by structure optimization method. The electronic structure and chemical bonding calculations were performed in terms of 2-dimensinal contour plots, band structure and density of state histograms within DFT using an accurate full potential linearize augmented plane-wave plus local orbital method (FP-LAPW + lo) having generalized gradient approximations (GGA) as implemented in WIEN2k package [9-11]. In this method the space is divided into non-overlapping muffin-tin (MT) spheres separated by 
interstitial region. The basis functions are expanded into spherical harmonic functions inside the muffin-tin sphere and the Fourier series in the interstitial region. The $\mathrm{k}$ and $\mathrm{E}$ convergences were checked by increasing the number of k points and energy convergences criteria. The cutoff energy which defines the separation of valence and core states was chosen as -6.0 Ry. In the irreducible part of the Brillouin zone, $15 \times 15 \times 15 \mathrm{k}$ points were used to calculate the total and partial density of states. The self consistent calculations were considered to be converged until the integrated charge difference between the last two iterations was less than $0.0001 \mathrm{ec}$. The Muffin Tin sphere radii (RMT) for each atom of $\mathrm{LaAuCd}$ and $\mathrm{La}_{2} \mathrm{Au}_{2} \mathrm{Cd}$ are taken as 2.5 for each atom. The Fermi energies for $\mathrm{LaAuCd}$ and $\mathrm{La}_{2} \mathrm{Au}_{2} \mathrm{Cd}$ are found to be $0.4557 \mathrm{eV}$ and $0.5203 \mathrm{eV}$, respectively.

Quasi-harmonic Debye model as implemented in Gibbs package [12] was used to calculate the thermodynamical behaviour of $\mathrm{LaAuCd}$ and $\mathrm{La}_{2} \mathrm{Au}_{2} \mathrm{Cd}$. In quasi-harmonic Debye model the non equilibrium Gibbs function $\mathrm{G}^{*}(\mathrm{~V} ; \mathrm{P}, \mathrm{T})$ is in the form of

$$
\mathrm{G} *(\mathrm{~V} ; \mathrm{P}, \mathrm{T})=\mathrm{E}(\mathrm{V})+\mathrm{PV}+\mathrm{A}_{\mathrm{Vib}}(\theta(\mathrm{V}) ; \mathrm{T})
$$

here $\mathrm{E}(\mathrm{V})$ is total energy per unit cell of $\mathrm{LaAuCd}$ and $\mathrm{La}_{2} \mathrm{Au}_{2} \mathrm{Cd}$, PV denotes the constant hydrostatic pressure, $\theta$ $(\mathrm{V})$ is the Debye temperature and $\mathrm{A}_{\text {vib }}$ is the vibration term which can be expressed using Debye model of the phonon density of states as [12]:

$$
\mathrm{A}_{\text {vib }}(\theta, T)=n k T\left[\frac{9 \theta}{8 \mathrm{~T}}+3 \ln \left(1-\mathrm{e}^{-\theta / \mathrm{T}}\right)-\mathrm{D}\left(\frac{\theta}{\mathrm{T}}\right)\right]
$$

here, $n$ is the number of atoms per formula unit, $\mathrm{D}(\theta / \mathrm{T})$ is the Debye integral. For an isotropic solid, $\theta$ can be expressed as [12]:

$$
\theta_{\mathrm{D}}=\frac{\hbar}{\mathrm{k}}\left[6 \pi \mathrm{V}^{1 / 2} \mathrm{n}\right]^{1 / 3} \mathrm{f}(\sigma) \sqrt{\frac{\mathrm{B}_{\mathrm{s}}}{\mathrm{M}}}
$$

here, $M$ is the molecular weight per unit cell and $B_{s}$ is the adiabatic bulk modulus, which is nearly equal to the static compressibility given by

(a)

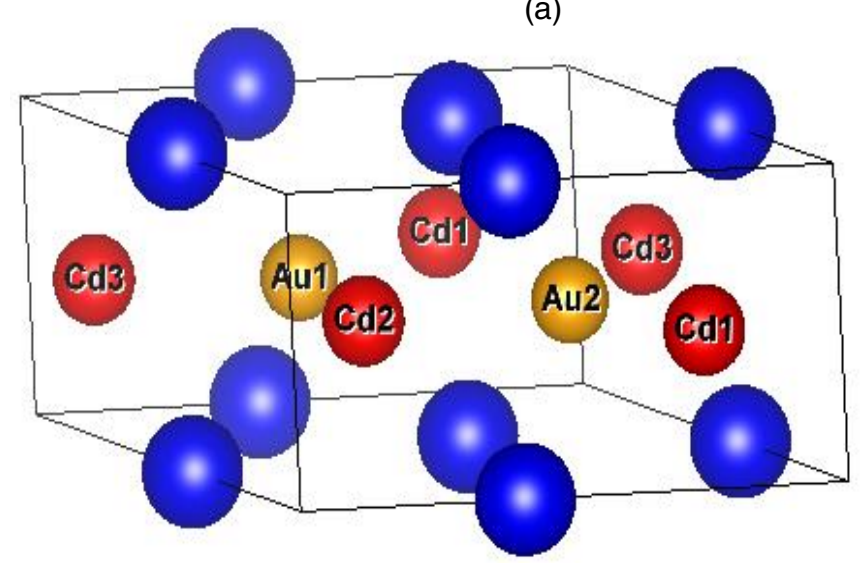

$$
B_{s}=B(V)=V \frac{d^{2} E(V)}{d V^{2}}
$$

And $f(\sigma)$ is given by

$$
f(\sigma)=\left[3\left\{2\left(\frac{2(1+\sigma)}{3(1-2 \sigma)}\right)^{3 / 2}+\left(\frac{1+\sigma}{3(1-\sigma)}\right)^{3 / 2}\right\}^{-1}\right]^{1 / 3}
$$

The non-equilibrium Gibbs functions as a function of (V; $\mathrm{P}, \mathrm{T})$ is minimized with respect to volume $\mathrm{V}$ :

$$
\left(\frac{\partial \mathrm{G} *(\mathrm{~V} ; \mathrm{P}, \mathrm{T})}{\partial \mathrm{V}}\right)_{\mathrm{P}, \mathrm{T}}=0
$$

By solving the above equation with respect to volume $\mathrm{V}$, one can obtain the thermal equation of state $(\mathrm{EOS}) \mathrm{V}(\mathrm{P}, \mathrm{T})$. The specific heat at constant volume and pressure $\left(\mathrm{C}_{\mathrm{V}}, \mathrm{C}_{\mathrm{p}}\right)$ and thermal expansion coefficient $\alpha$ by using the expressions [12]:

$$
\begin{gathered}
C_{v}=3 n k\left[4 D\left(\frac{\theta}{T}\right)-\frac{3 \theta / T}{e^{\theta / T}-1}\right] \\
S=n k\left[4 D\left(\frac{\theta}{T}\right)-3 \ln \left(e^{\theta / T}-1\right)\right] \\
\alpha=\frac{\gamma C_{v}}{B_{T} V} \\
C_{p}=C_{v}(1+\alpha \gamma T)
\end{gathered}
$$

here $\gamma$ represents the Grüneisen parameter, expressed as

$$
\gamma=-\frac{\mathrm{d} \ln \theta(\mathrm{V})}{\mathrm{d} \ln \mathrm{V}}
$$

\section{RESULTS AND DISCUSSION}

Structural properties: The unit cell structure of $\mathrm{LaAuCd}$ and $\mathrm{La}_{2} \mathrm{Au}_{2} \mathrm{Cd}$ are illustrated in the Fig. 1(a) and 1(b), respectively. The structural parameters viz. lattice parameters, bulk modulus and its first order pressure derivative have been esti-

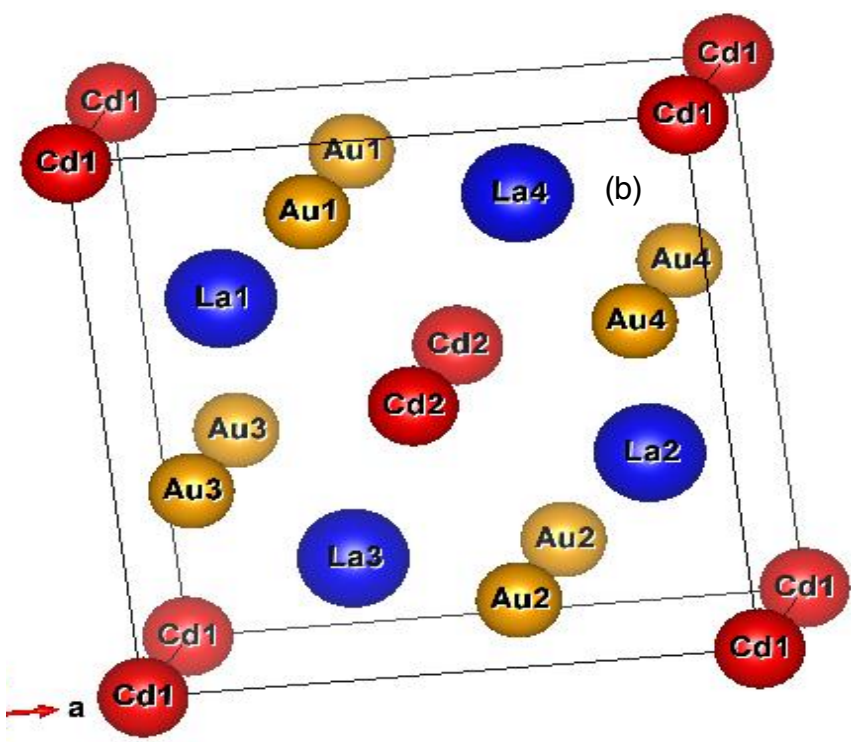

Fig. 1. (Colour online) unit cell structure of (a) $\mathrm{LaAuCd}$ and (b) $\mathrm{La}_{2} \mathrm{Au}_{2} \mathrm{Cd}$ using VESTA package 
mated through fitting the total energy data with the Murnaghan equation of state [13] given by:

$$
\mathrm{E}_{\text {total }}=\mathrm{E}_{0}(\mathrm{~V})+\frac{\mathrm{B}_{0} \mathrm{~V}_{0}}{\mathrm{~B}_{0}^{\prime}\left(\mathrm{B}_{0}^{\prime}-1\right)}\left[\mathrm{B}_{0}\left(1-\frac{\mathrm{V}_{0}}{\mathrm{~V}}\right)+\left(\frac{\mathrm{V}_{0}}{\mathrm{~V}}\right)^{\mathrm{B}_{0}^{\prime}}-1\right]
$$

where, $\mathrm{E}_{0}$ and $\mathrm{V}_{0}$ are the energy and volume at equilibrium. $\mathrm{B}_{0}$ and $\mathrm{B}_{0}{ }^{\prime}$ are the equilibrium bulk modulus and its first order pressure derivative.

The calculated lattice parameters $\left(\mathrm{a}_{0}, \mathrm{c}_{0}\right)$, bulk modulus $\left(\mathrm{B}_{0}\right)$ and its first order pressure derivative $\left(\mathrm{B}_{0}{ }^{\prime}\right)$ are shown in Table-1. Calculated values of lattice parameters show good agreement with experimental values [2]. Bulk modulus $\left(\mathrm{B}_{0}\right)$ is a material property indicating the degree of resistance of a material to compression. Larger the bulk modulus, greater is the degree of resistance. It can be observed from Table- 1 that $\mathrm{B}_{\mathrm{LaAuCd}}<\mathrm{B}_{\mathrm{La2Au2Cd}}$, which indicates that degree of resistance of $\mathrm{La}_{2} \mathrm{Au}_{2} \mathrm{Cd}$ is larger than $\mathrm{LaAuCd}$.

\section{TABLE-1}

LATTICE PARAMETERS, $\mathrm{a}_{0}, \mathrm{c}_{0}(\AA)$, BULK MODULUS, $\mathrm{B}_{0}(\mathrm{GPa})$ AND PRESSURE DERIVATIVE OF BULK MODULUS, $\mathrm{B}_{0}$ ' (GPa) IN EQUILIBRIUM CONDITION FOR LaAuCd AND $\mathrm{La}_{2} \mathrm{Au}_{2} \mathrm{Cd}$ USING PBE-GGA

\begin{tabular}{ccc}
\hline & $\mathrm{LaAuCd}$ & $\mathrm{La}_{2} \mathrm{Au}_{2} \mathrm{Cd}$ \\
\hline $\mathrm{a}_{0}, \mathrm{c}_{0}$ & $7.81,4.21$ & $8.01,4.15$ \\
Expt. [3] & $7.86,4.15$ & $8.09,4.00$ \\
$\mathrm{~B}_{0}$ & 54.50 & 81.00 \\
$\mathrm{~B}_{0}{ }^{\prime}$ & 4.95 & 6.00 \\
$\mathrm{~V}_{0}$ & 1521 & 1830 \\
\hline
\end{tabular}

The stability of the material is described by equilibrium energy $\left(\mathrm{E}_{0}\right)$ versus volume $\left(\mathrm{V}_{0}\right)$ curves which are illustrated in Fig. 2(a) and 2(b) for $\mathrm{LaAuCd}$ and $\mathrm{La}_{2} \mathrm{Au}_{2} \mathrm{Cd}$. It is clear from these figures that both the compounds are stable with equilibrium energy values $\left(\mathrm{E}_{0}\right)-160753.95 \mathrm{eV}$ and -242749.10 $\mathrm{eV}$ at the equilibrium volume $\left(\mathrm{V}_{0}\right) 1516.14$ a.u. ${ }^{3}$ and 1819.42 a.u. ${ }^{3}$ for $\mathrm{LaAuCd}$ and $\mathrm{La}_{2} \mathrm{Au}_{2} \mathrm{Cd}$, respectively. It is evident that equilibrium energy of $\mathrm{LaAuCd}$ is larger than $\mathrm{La}_{2} \mathrm{Au}_{2} \mathrm{Cd}$ while volume of $\mathrm{LaAuCd}$ is smaller than $\mathrm{La}_{2} \mathrm{Au}_{2} \mathrm{Cd}$. This indicates that the stability of $\mathrm{La}_{2} \mathrm{Au}_{2} \mathrm{Cd}$ is larger than $\mathrm{LaAuCd}$ molecules. This is due to larger weight of $\mathrm{La}_{2} \mathrm{Au}_{2} \mathrm{Cd}$ than $\mathrm{LaAuCd}$ because

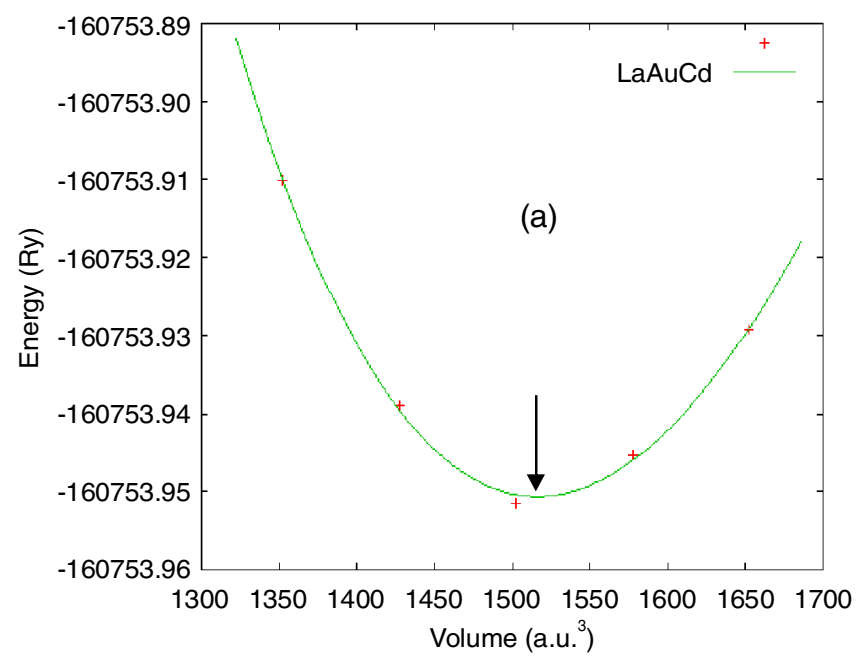

as molecular weight increases, the molecule needs smaller volume to vibrate in the unit cell to occupy equilibrium state. The equilibrium energy decreases and equilibrium unit cell volume increases [14].

Electronic bonding characteristics: In order to investigate the nature of chemical bonding in $\mathrm{LaAuCd}$ and $\mathrm{La}_{2} \mathrm{Au}_{2} \mathrm{Cd}$, total valance charge density distribution (contour plots) has been shown in Fig. 3(a) and 3(b), respectively. The charge density distribution depict that there is no bonding charge to link $\mathrm{La}, \mathrm{Au}$ or $\mathrm{Cd}$ atoms in the interstitial region and charge density distribution is spherically symmetric around each atom, indicates ionic character of both the compounds.

To know more about bonding properties, electron dispersion curves and total partial density of states of LaAuCd and $\mathrm{La}_{2} \mathrm{Au}_{2} \mathrm{Cd}$ have been plotted. The calculated electron dispersion curves along high symmetry directions $\mathrm{R}, \Gamma, \mathrm{X}$ and $\mathrm{M}$ in the irreducible part of Brillouin zone for $\mathrm{LaAuCd}$ and $\mathrm{La}_{2} \mathrm{Au}_{2} \mathrm{Cd}$ were shown in the Fig. 4(a) and 4(b), respectively. These figures indicate that most of the valence bands lie from $-8.00 \mathrm{eV}$ to $0.0 \mathrm{eV}$ below the Fermi level (where Fermi level, $\mathrm{E}_{\mathrm{F}}$ is considered at origin). Fig. 4(a) and 4(b) depict that the bands at $-5.0 \mathrm{eV}$ are denser in case of $\mathrm{La}_{2} \mathrm{Au}_{2} \mathrm{Cd}$ than $\mathrm{LaAuCd}$. These bands are denser mainly due to hybridization of La-p and Au-d orbitals [(Fig. 5(a-h) for LaAuCd and Fig. 6(a-h) for $\mathrm{La}_{2} \mathrm{Au}_{2} \mathrm{Cd}$ of DOS]. Furthermore, electron dispersion histograms of $\mathrm{LaAuCd}$ and $\mathrm{La}_{2} \mathrm{Au}_{2} \mathrm{Cd}$ confirm no band gap as valance bands and conduction bands are overlapping at the Fermi level, indicating $\mathrm{LaAuCd}$ and $\mathrm{La}_{2} \mathrm{Au}_{2} \mathrm{Cd}$ have metallic character. This metallic character in both the compounds is caused by bonding of $\mathrm{p}$ orbitals of $\mathrm{La}, \mathrm{Au}$ and $\mathrm{Cd}$ [(Fig. 5(c,e,g) for $\mathrm{LaAuCd}$ and 6(c, e, g) for $\mathrm{La}_{2} \mathrm{Au}_{2} \mathrm{Cd}$ of DOS].

Now, total density of states (TDOS) and partial density of states (PDOS) plots have been shown in Fig. 5(a-h) for LaAuCd and $6(\mathrm{a}-\mathrm{h})$ for $\mathrm{La}_{2} \mathrm{Au}_{2} \mathrm{Cd}$, respectively. In case of $\mathrm{LaAuCd}$, Fig. 5(a) depicts that there are mainly two peaks below the Fermi level at around $-8.0 \mathrm{eV}$ and $-5.0 \mathrm{eV}$. The peak at around $-8.0 \mathrm{eV}$ is mainly due to $\mathrm{Cd}-\mathrm{d}$ orbitals with small contribution of La-p orbitals [Fig. 5(c,h)]. The sharp peak at around -5.0 $\mathrm{eV}$ is caused by mainly Au-d orbitals with small contribution of La-p and Au-s orbitals with small contribution of Au-s orbitals. The orbitals at the Fermi level are due to hybridization

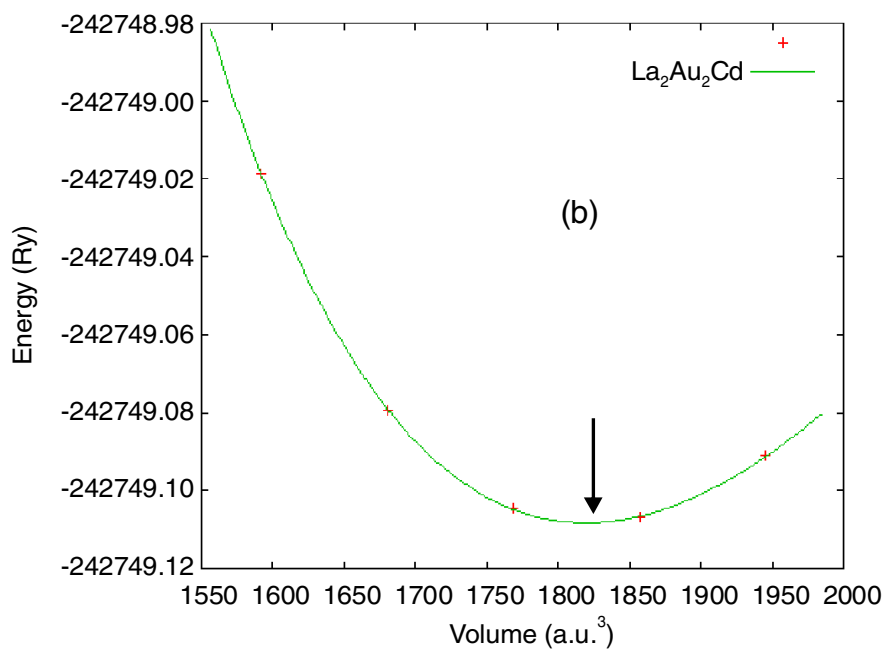

Fig. 2. (Colour online) total energy versus volume curve for (a) $\mathrm{LaAuCd}$ and (b) $\mathrm{La}_{2} \mathrm{Au}_{2} \mathrm{Cd}$ with PBE-GGA approximation 


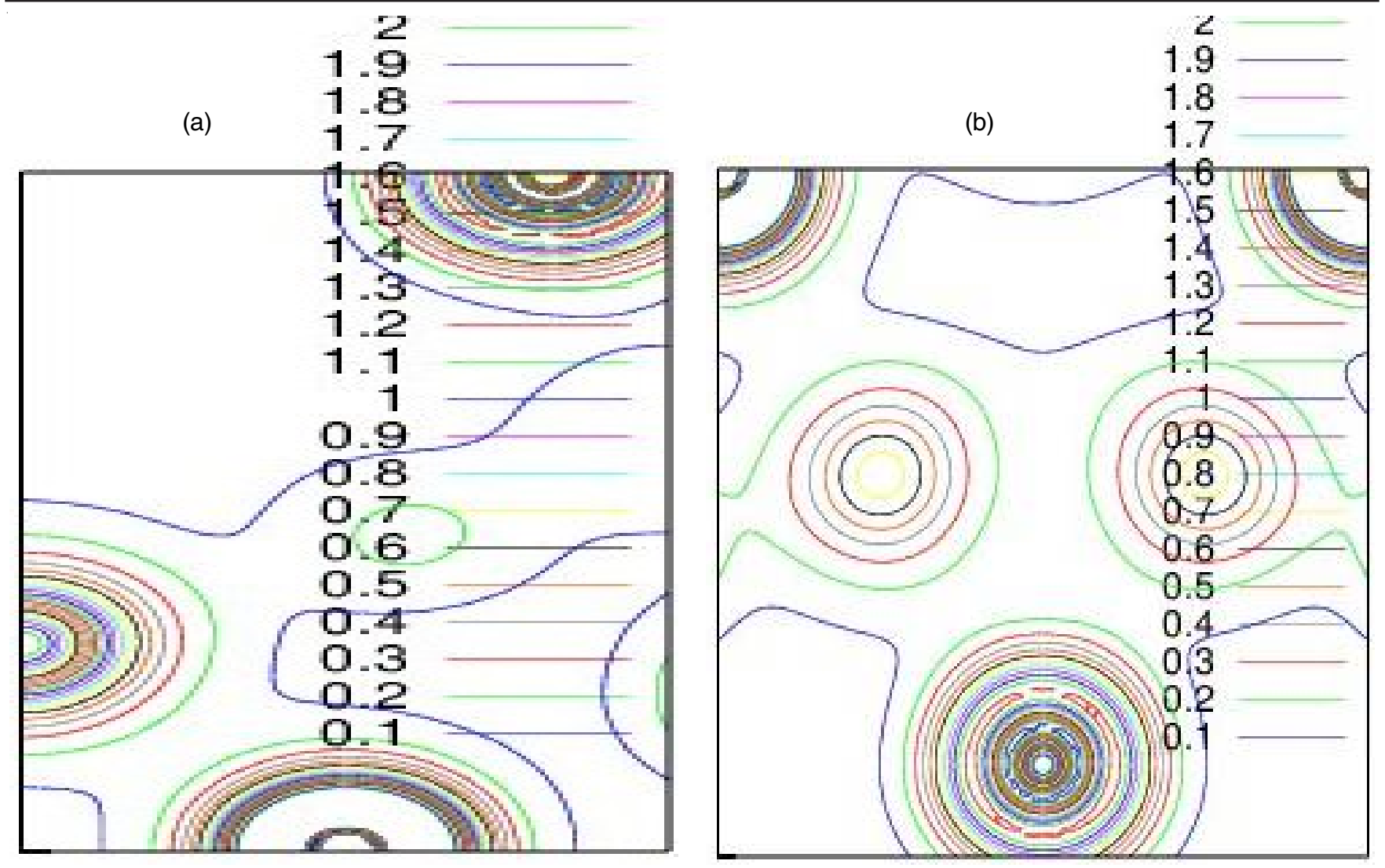

Fig. 3. (Colour online) 2-d contour plots of valance charge density distribution of (a) $\mathrm{LaAuCd}$ and (b) $\mathrm{La}_{2} \mathrm{Au}_{2} \mathrm{Cd}$
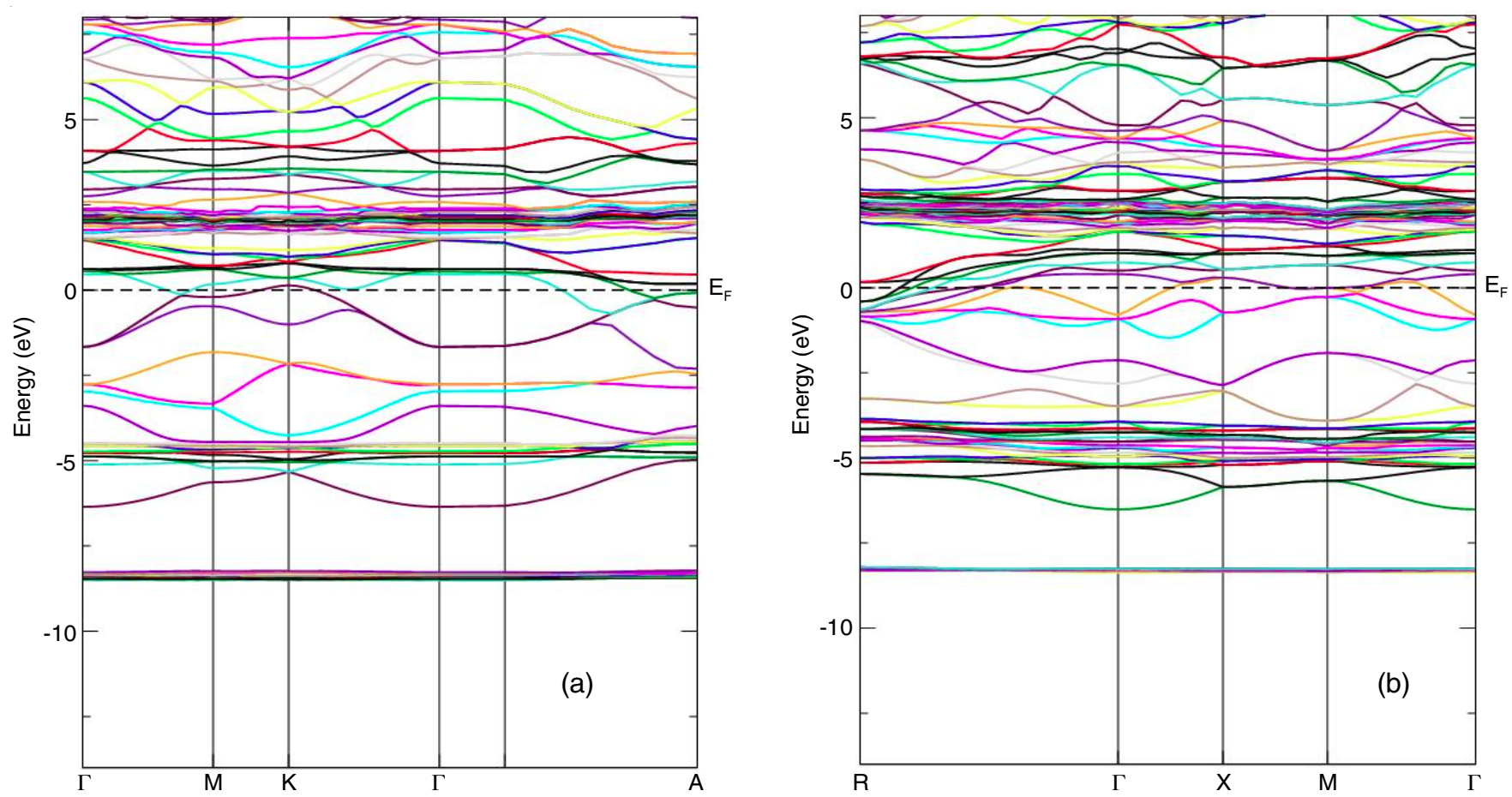

Fig. 4. (Colour online) electron dispersion curves along high symmetry directions in the Brillouin zone for (a) $\mathrm{LaAuCd} \mathrm{and}(\mathrm{b}) \mathrm{La}_{2} \mathrm{Au}_{2} \mathrm{Cd}$ with PBE-GGA approximation

of La-p, Au-p and Cd-p orbitals [Fig. 5(c,e,g)]. A sharp peak of density of state (DOS) is also existed above the Fermi level at around $2.0 \mathrm{eV}$. These are empty states and available for the conduction. These orbitals are mainly contributed by local La-f orbitals [Fig. 5(b,d)]. Almost, all features of TDOS and PDOS for $\mathrm{La}_{2} \mathrm{Au}_{2} \mathrm{Cd}$ are found to similar except that intensity of TDOS of each peak of $\mathrm{La}_{2} \mathrm{Au}_{2} \mathrm{Cd}$ is larger than $\mathrm{LaAuCd}$. Fig. 6(a-h) can be discussed in similar fashion to LaAuCd. 

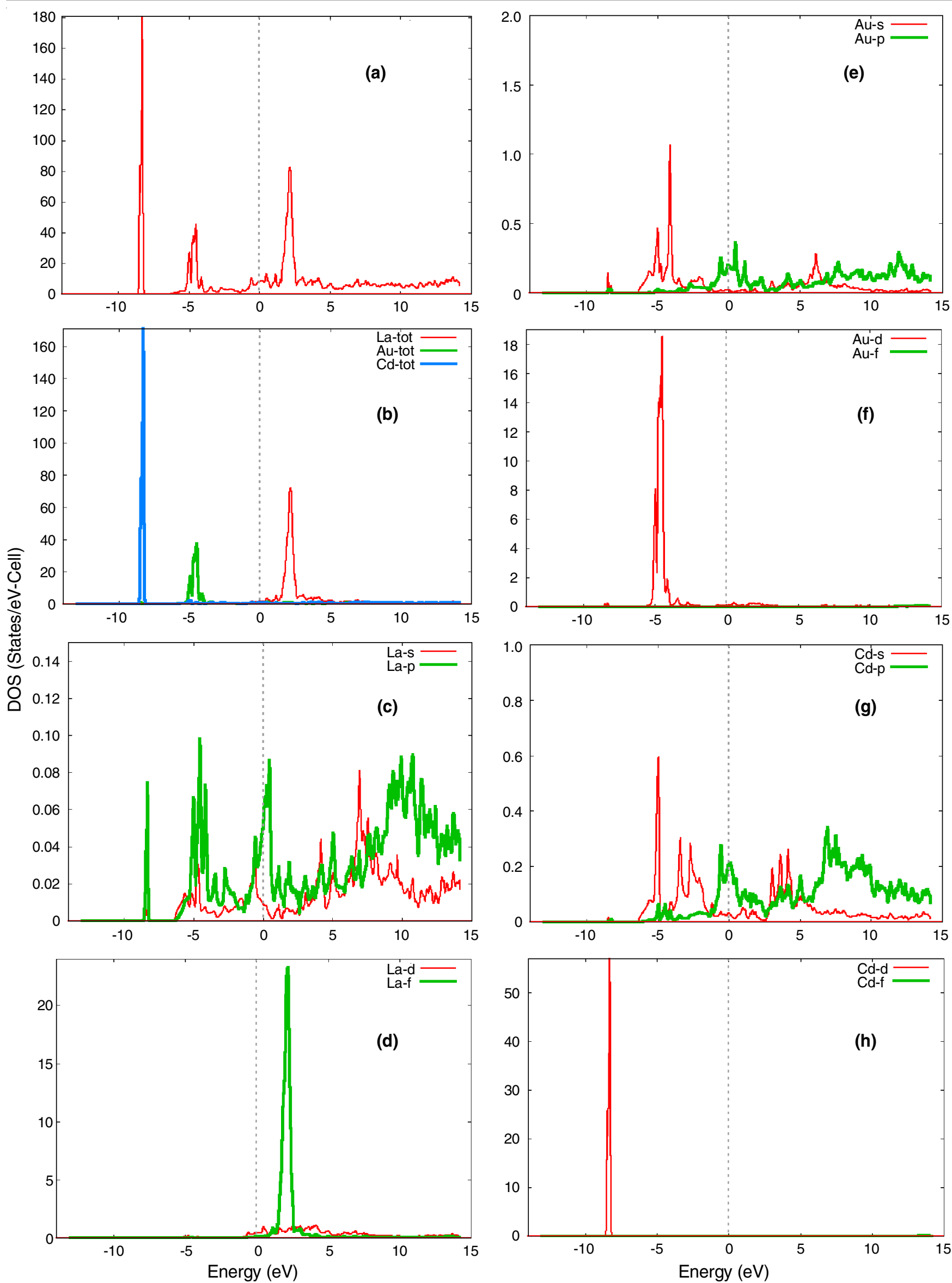

Fig. 5. (Colour online) Calculated total density of states for (a) LaAuCd, (b) La, Au and Cd. Partial density of states for (c) La-s and La-p (d) La-d, La-f (e) Au-s, Au-p; (f) Au-d, Au-f and (g) Cd-s,Cd-p and (h) Cd-d, Cd-f orbitals with PBE-GGA approximation 

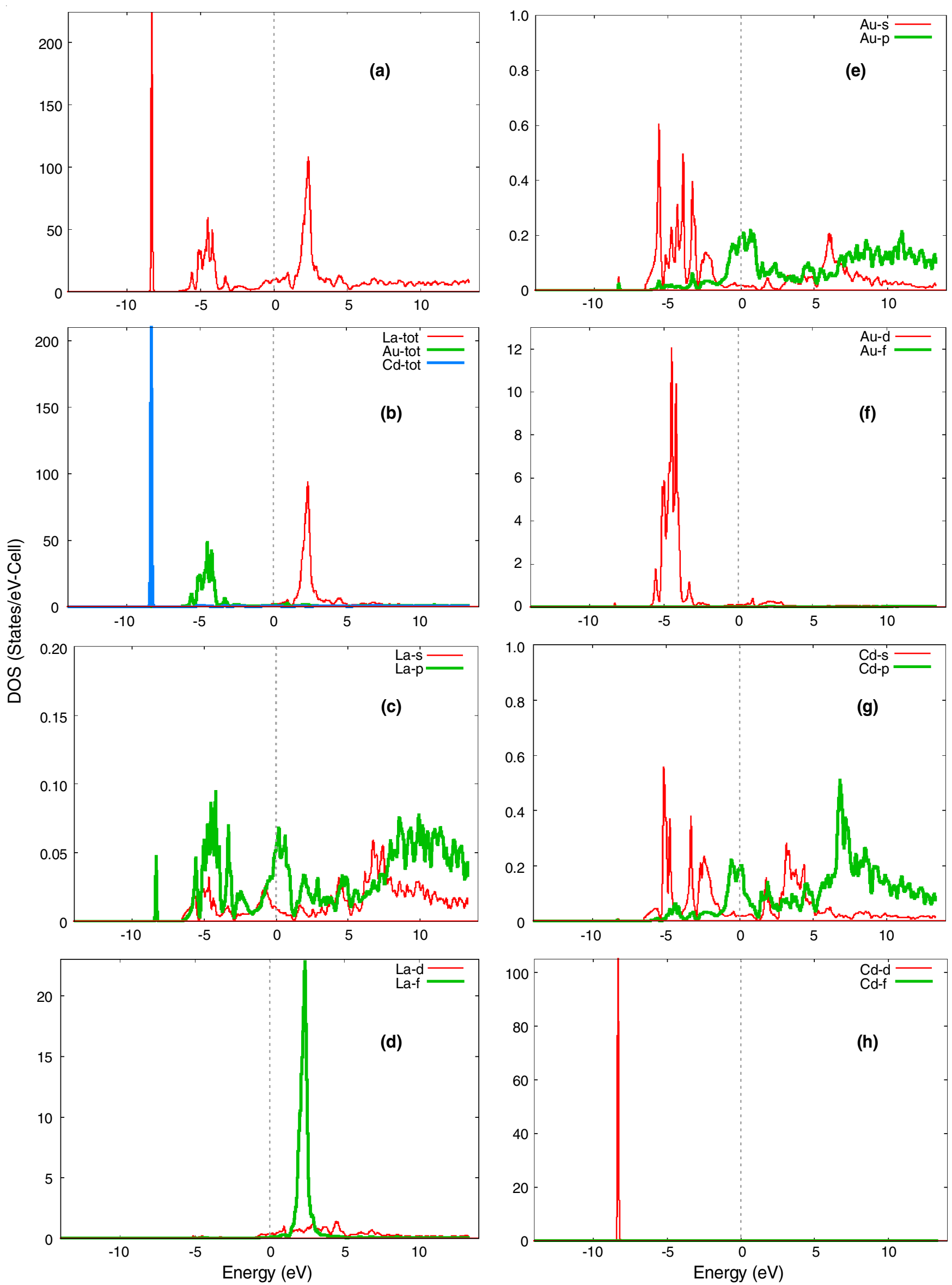

Fig. 6. (Colour online) calculated total density of states for (a) $\mathrm{La}_{2} \mathrm{Au}_{2} \mathrm{Cd}$, (b) La, Au and Cd. Partial density of states for (c) La-s and La-p (d) La-d, La-f (e) Au-s, Au-p; (f) Au-d, Au-f and (g) Cd-s,Cd-p and (h) Cd-d, Cd-f orbitals with PBE-GGA approximation 
Thermodynamic properties: Quasi-harmonic Debye model [12] has been successfully used to calculate the temperature and pressure dependent thermodynamic properties of $\mathrm{LaAuCd}$ and $\mathrm{La}_{2} \mathrm{Au}_{2} \mathrm{Cd}$. The effect of temperature has been studied in a wide temperature range $0-300 \mathrm{~K}$ for both the compounds whereas effect of pressure has been studied in pressure range 0-40 GPa for $\mathrm{LaAuCd}$ and $0-180 \mathrm{GPa}$ for $\mathrm{La}_{2} \mathrm{Au}_{2} \mathrm{Cd}$. Temperature and pressure dependent variations in volume $(\mathrm{V})$, bulk modulus (B), Debye temperature $\left(\theta_{\mathrm{D}}\right)$, Specific heat $\left(\mathrm{C}_{\mathrm{V}}\right)$, thermal expansion coefficient $(\alpha)$ and entropy (S) for LaAuCd and $\mathrm{La}_{2} \mathrm{Au}_{2} \mathrm{Cd}$ are depicted in Fig. 7-12. Fig. 7(a) and 7(b) demonstrate the temperature dependent variation in $\mathrm{V}$ and Fig. 7(c) and 7(d) demonstrate the pressure dependent variation in $\mathrm{V}$ at different temperature for $\mathrm{LaAuCd}$ and $\mathrm{La}_{2} \mathrm{Au}_{2} \mathrm{Cd}$, respectively. Furthermore, these figures indicate that unit cell volume (V) increases with temperature while it decreases with pressure. Unit cell volume increases with temperature due to the expansion of dimensions of unit cell with temperature and decreases with pressure as dimensions of unit cell are compressed with increasing the pressure.

Fig. 8(a) and 8(b) display the variation in bulk modulus (B) with temperature while Fig. 8(c) and 8(d) display the variation in $\mathrm{B}$ with pressure for $\mathrm{LaAuCd}$ and $\mathrm{La}_{2} \mathrm{Au}_{2} \mathrm{Cd}$, respectively. Value of $\mathrm{B}$ provides an idea about the degree of resistance of $\mathrm{LaAuCd}$ and $\mathrm{La}_{2} \mathrm{Au}_{2} \mathrm{Cd}$ material. Fig. 8(a,b,c,d) exhibit
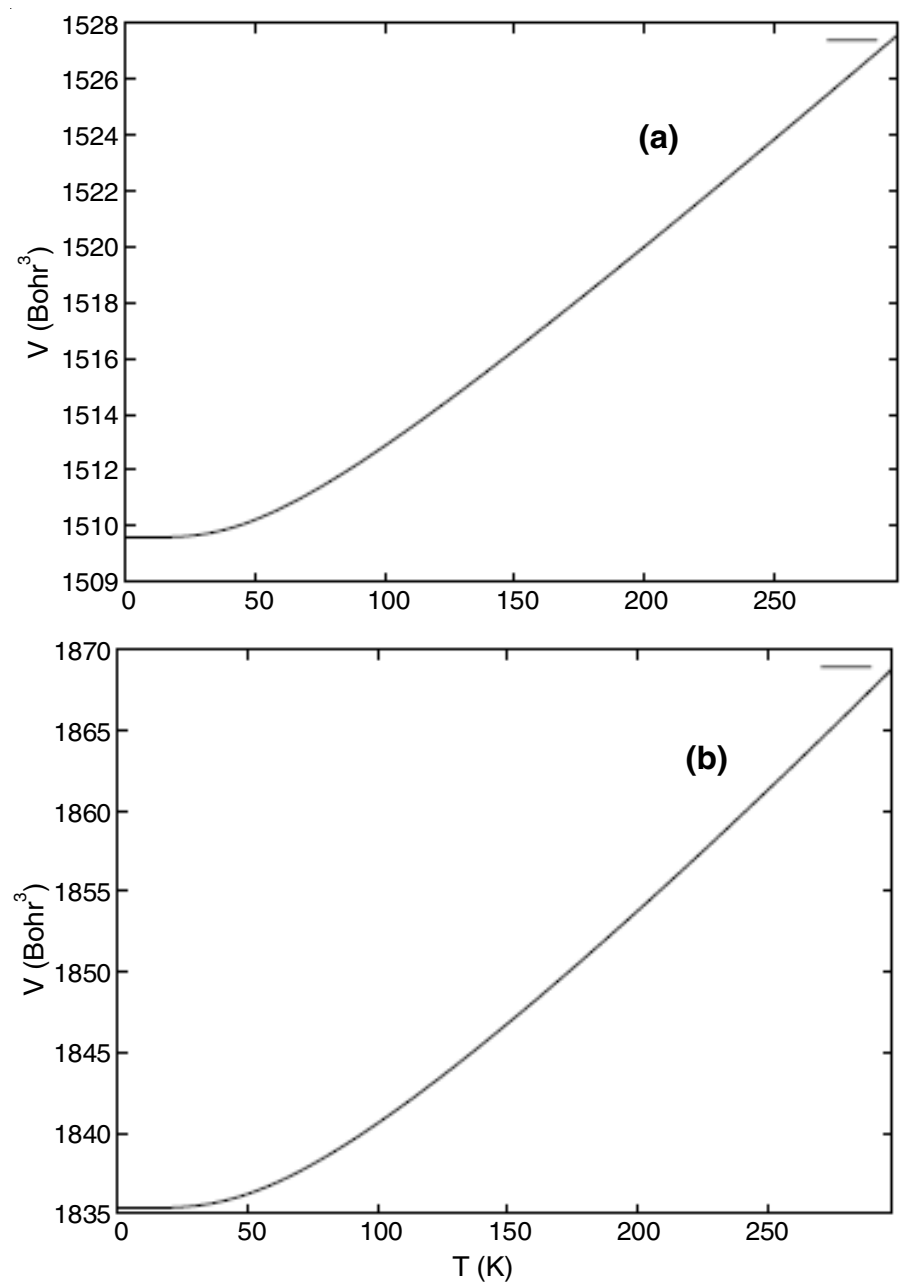

Fig. 7. Temperature induced variation in volume, $\mathrm{V}$ for (a) $\mathrm{LaAuCd}$ $\mathrm{LaAuCd}(\mathrm{e}) \mathrm{La}_{2} \mathrm{Au}_{2} \mathrm{Cd}$ that $\mathrm{B}$ decreases with the temperature whereas increases with pressure with linear trend at each temperature. This decrease in bulk modulus with the temperature and increase with pressure is caused by change in unit cell volume with temperature and pressure (which increases with increasing the temperature while decreases with increasing the pressure), signify that both the compounds become softer with increasing the temperature whereas become harder with increasing the pressure [15-17]. Furthermore, bulk modulus is directly related to its valance electron density. High value of bulk modulus implies larger valance electron density. In our case, $\mathrm{B}_{\mathrm{LaAuCd}}<\mathrm{B}_{\mathrm{La2Au2Cd} \text {. This }}$ implies that $\mathrm{La}_{2} \mathrm{Au}_{2} \mathrm{Cd}$ has greater valance electron density than LaAuCd [16].

The Debye temperature, $\theta_{\mathrm{D}}$ is the temperature of a crystal's highest normal mode of vibration, i.e. the highest temperature that can be achieved due to a single normal vibration [18]. Fig. $9(\mathrm{a}, \mathrm{b}, \mathrm{c}, \mathrm{d})$, depict the variation of Debye temperature $\left(\theta_{\mathrm{D}}\right)$ with temperature and pressure. It is clear that $\theta_{\mathrm{D}}$ decreases at slow rate with temperature while increases at faster rate with pressure for both the compounds. The slow variation in $\theta_{D}$ with temperature reflects small impact of temperature on $\theta_{D}$ but high impact of pressure on $\theta_{\mathrm{D}}$. The slow variation of $\theta_{\mathrm{D}}$ with temperature also reflects the fact that thermal vibration frequency of the atoms in $\mathrm{LaAuCd}$ and $\mathrm{La}_{2} \mathrm{Au}_{2} \mathrm{Cd}$ changes slowly with the temperature while changes at faster rate with
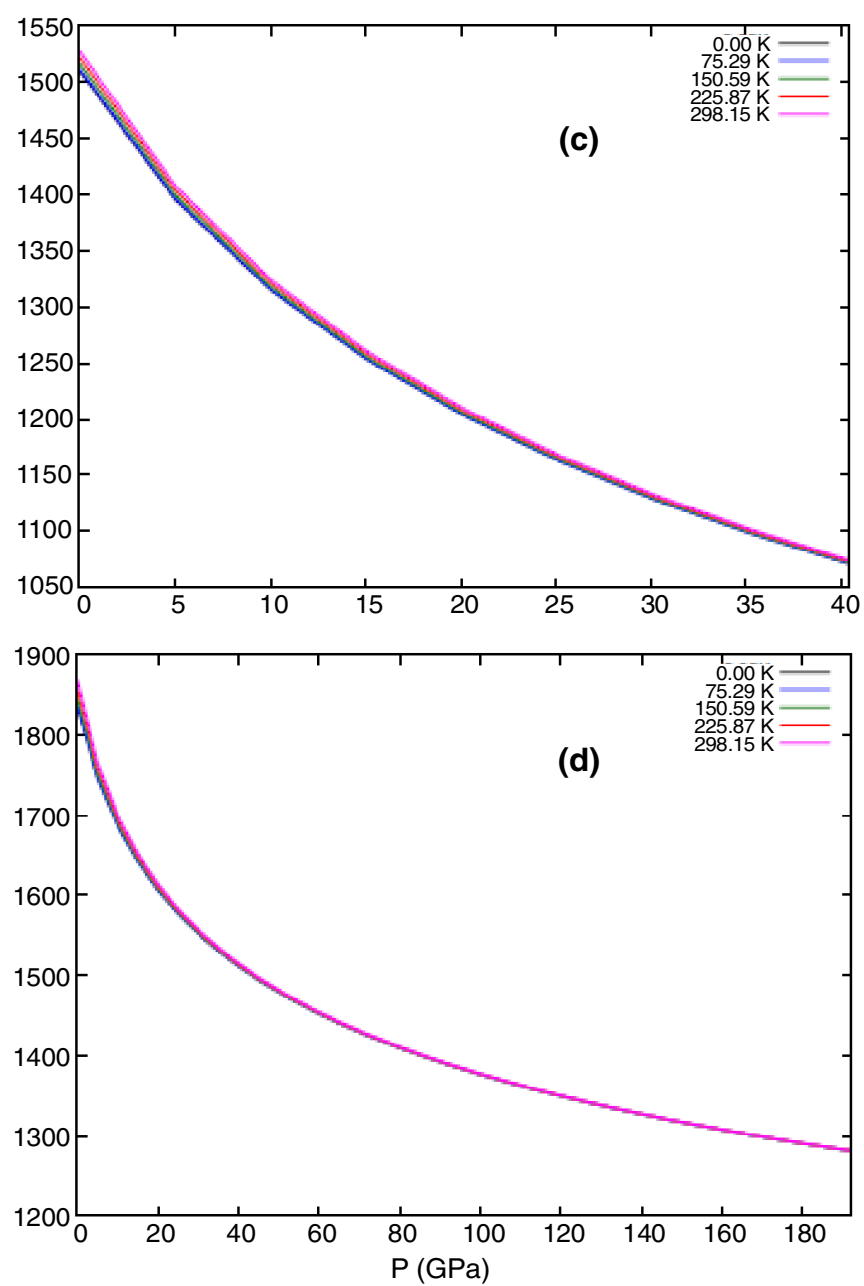

(b) $\mathrm{La}_{2} \mathrm{Au}_{2} \mathrm{Cd}$ and pressure induced variation in volume, $\mathrm{V}$ for (d) 

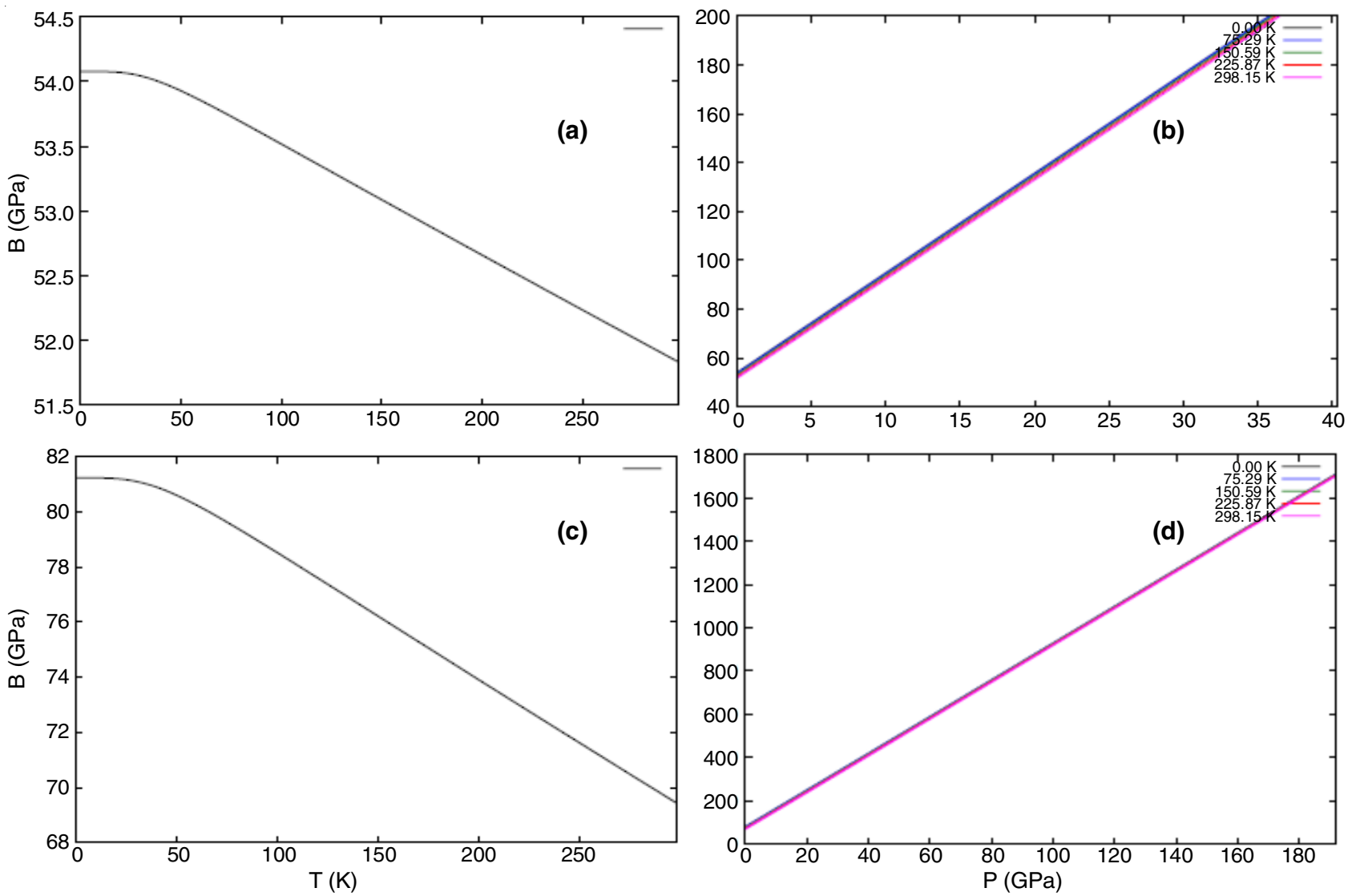

Fig. 8. Temperature induced variation in bulk modulus, B for (a) $\mathrm{LaAuCd}$ (b) $\mathrm{La}_{2} \mathrm{Au}_{2} \mathrm{Cd}$ and Pressure induced variation in Volume, $\mathrm{V}$ for (d) $\mathrm{LaAuCd}$ (e) $\mathrm{La}_{2} \mathrm{Au}_{2} \mathrm{Cd}$
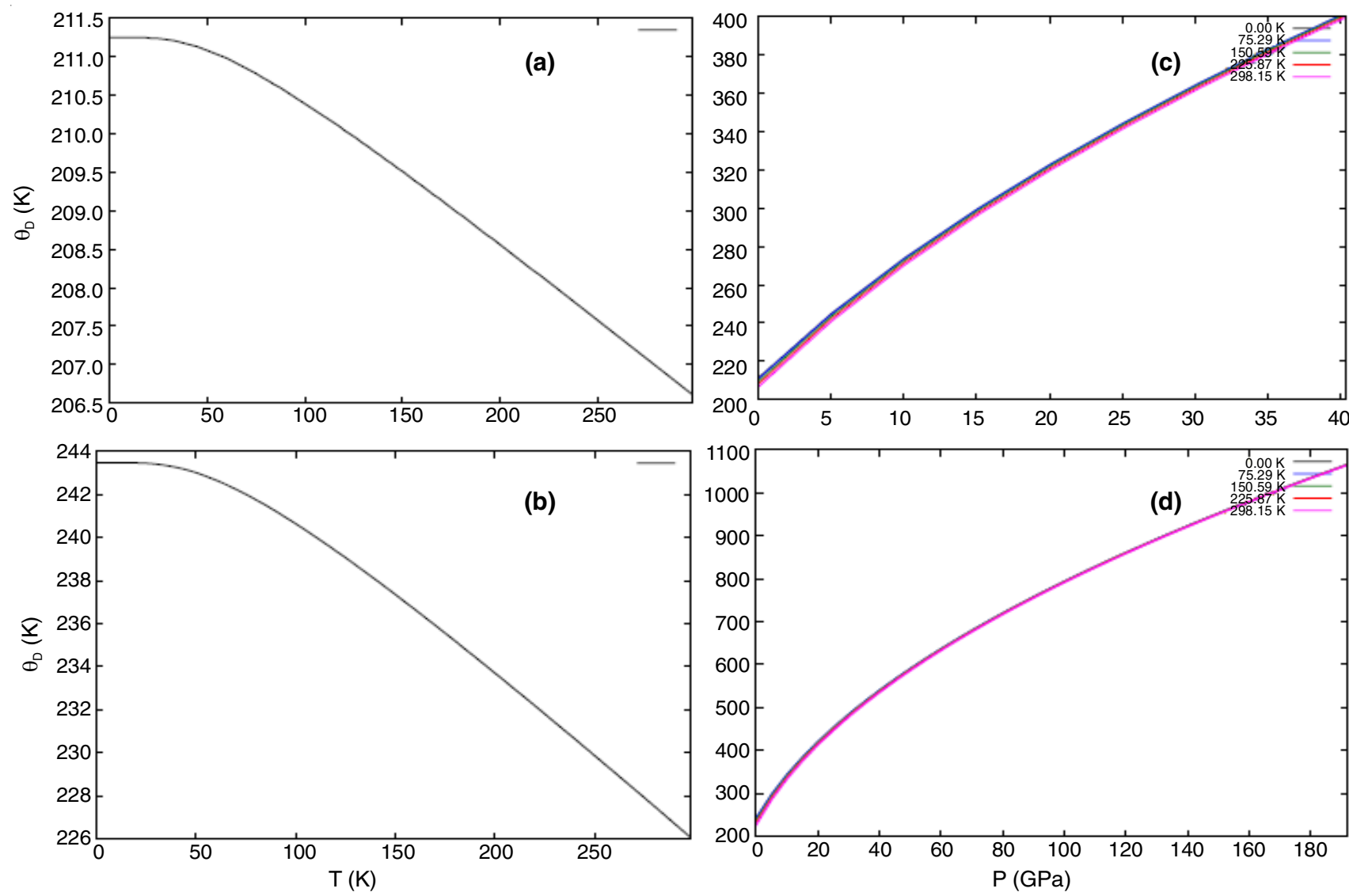

Fig. 9. Temperature induced variation in Debye temperature, $\theta_{\mathrm{D}}$ for (a) $\mathrm{LaAuCd}(\mathrm{b}) \mathrm{La}_{2} \mathrm{Au}_{2} \mathrm{Cd}$ and pressure induced variation in volume, $\mathrm{V}$ for (d) $\mathrm{LaAuCd}$ (e) $\mathrm{La}_{2} \mathrm{Au}_{2} \mathrm{Cd}$ 

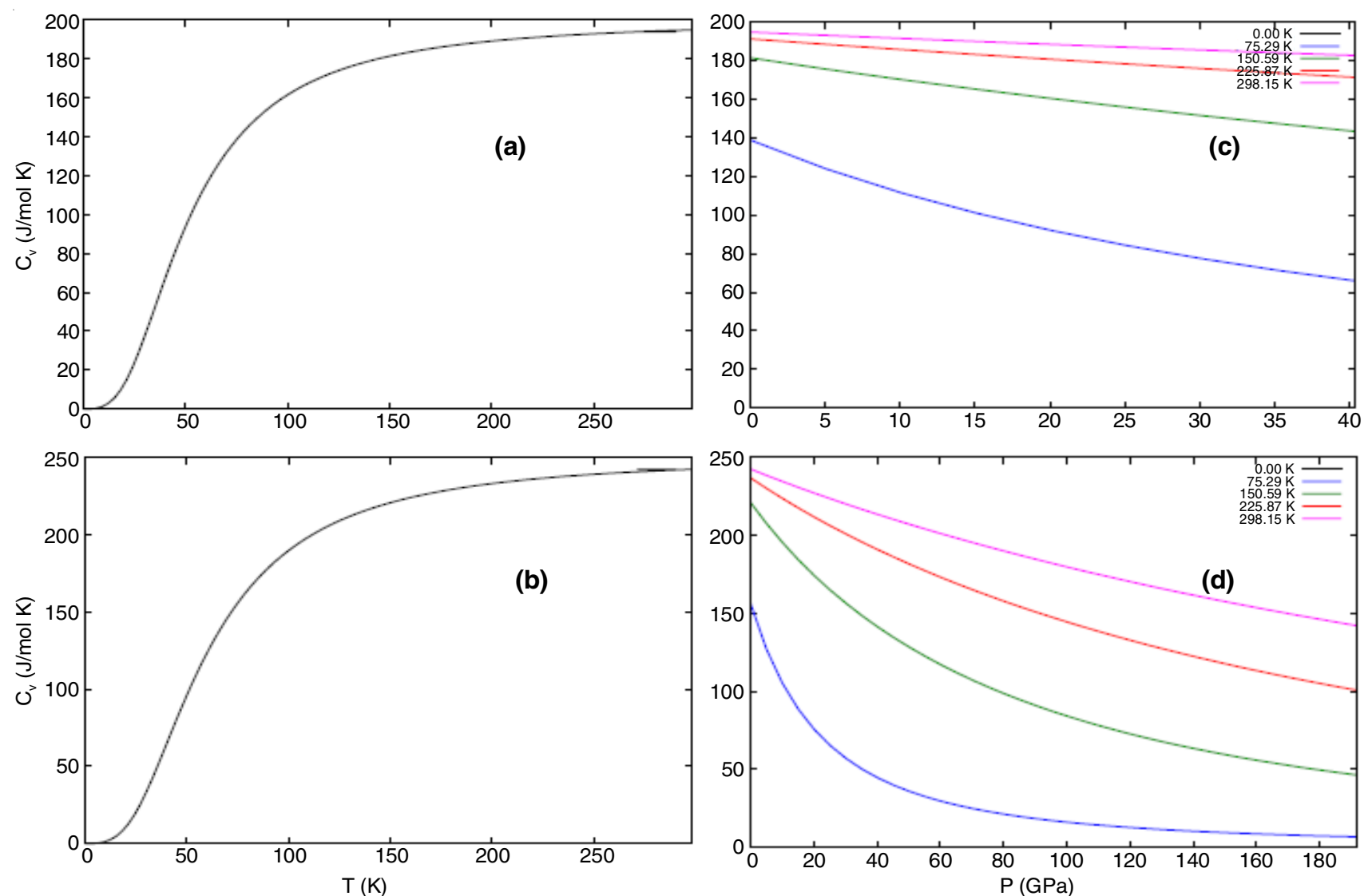

Fig. 10. Temperature induced variation in specific heat, $\mathrm{C}_{\mathrm{v}}$ for (a) $\mathrm{LaAuCd}(\mathrm{b}) \mathrm{La}_{2} \mathrm{Au}_{2} \mathrm{Cd}_{\text {and }}$ Pressure induced variation in Volume, $\mathrm{V}$ for (d) $\mathrm{LaAuCd}(\mathrm{e}) \mathrm{La}_{2} \mathrm{Au}_{2} \mathrm{Cd}$
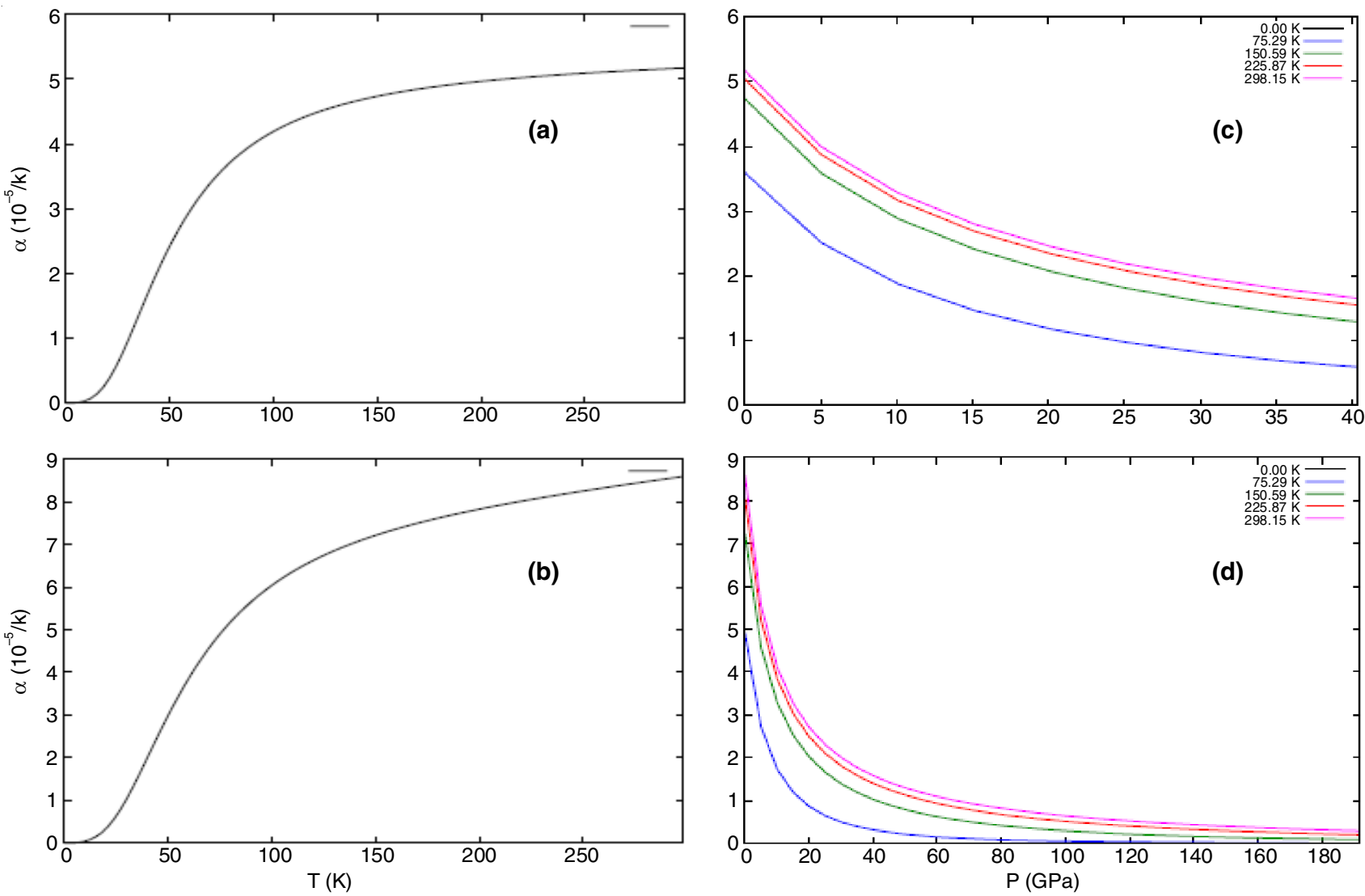

Fig. 11. Temperature induced variation in thermal expansion coefficient, $\alpha$ for (a) $\mathrm{LaAuCd}$ (b) $\mathrm{La}_{2} \mathrm{Au}_{2} \mathrm{Cd}_{\text {and }}$ Pressure induced variation in Volume, $\mathrm{V}$ for (d) $\mathrm{LaAuCd}(\mathrm{e}) \mathrm{La}_{2} \mathrm{Au}_{2} \mathrm{Cd}$ 

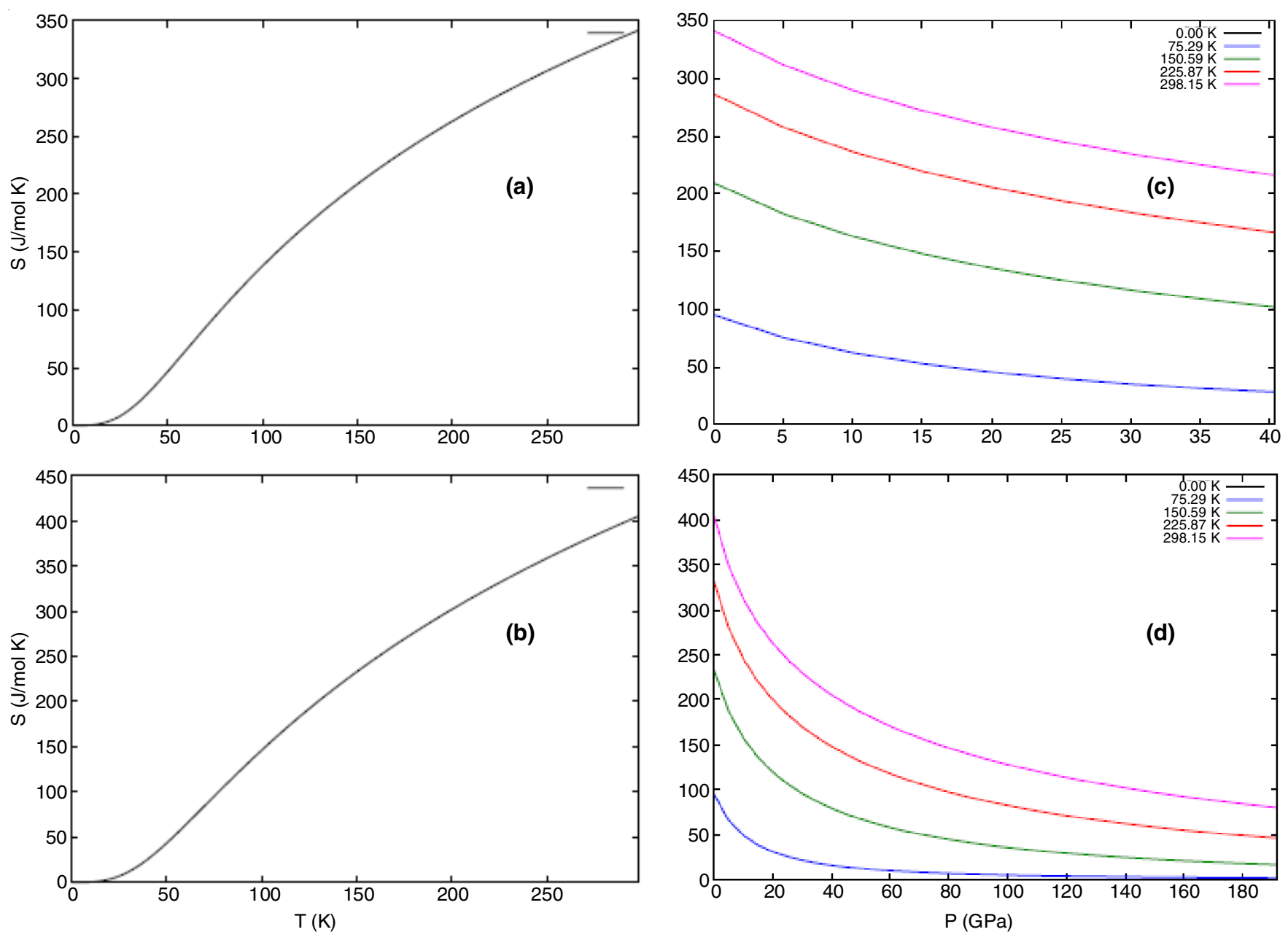

Fig. 12. Temperature induced variation in enthalpy (S) for (a) $\mathrm{LaAuCd}$ $\mathrm{LaAuCd}(\mathrm{e}) \mathrm{La}_{2} \mathrm{Au}_{2} \mathrm{Cd}$

pressure. Furthermore, it can be observed from Table-2 that $\theta_{\mathrm{D}}$ of $\mathrm{La}_{2} \mathrm{Au}_{2} \mathrm{Cd}$ is larger than $\mathrm{LaAuCd}$, reflecting that thermal vibrational frequency of $\mathrm{La}_{2} \mathrm{Au}_{2} \mathrm{Cd}$ is larger than $\mathrm{LaAuCd}$.

\begin{tabular}{|c|c|c|}
\hline \multicolumn{3}{|c|}{$\begin{array}{c}\text { TABLE-2 } \\
\text { CALCULATED FERMI ENERGY E } \mathrm{f}_{\mathrm{f}}(\mathrm{eV}) \text { AT } 0 \mathrm{~K} \text { AND } \\
\text { DEBYE TEMPERATURE } \theta_{\mathrm{D}}(\mathrm{K}) \text { GRÜNEISEN PARAMETER, } \gamma, \\
\text { THERMAL EXPANSION COEFFICIENT, } \alpha\left(10^{-5} / \mathrm{K}\right) \text {, SPECIFIC } \\
\text { HEAT C } \mathrm{C}_{\mathrm{v}}(\mathrm{J} / \mathrm{mol} \mathrm{K}) \text { AND ENTHALPY, S }(\mathrm{J} / \mathrm{molK}) \text { AT } 298 \mathrm{~K} \\
\text { FOR LaAuCd AND La } \mathrm{Au}_{2} \mathrm{Cd} \text { USING PBE-GGA }\end{array}$} \\
\hline & LaAuCd & $\mathrm{La}_{2} \mathrm{Au}_{2} \mathrm{Cd}$ \\
\hline $\mathrm{E}_{\mathrm{f}}$ & 0.45 & 0.52 \\
\hline$\theta_{\mathrm{D}}$ & 206 & 226 \\
\hline$\gamma$ & 1.87 & 4.10 \\
\hline$\alpha$ & 5.20 & 8.50 \\
\hline $\mathrm{C}_{\mathrm{v}}$ & 192 & 242 \\
\hline $\mathrm{S}$ & 345 & 401 \\
\hline
\end{tabular}

The temperature and pressure dependent behaviour of the calculated heat capacity at constant volume $\left(\mathrm{C}_{\mathrm{V}}\right)$ is shown in Fig. 10(a,b,c,d), respectively. These figures show that $\mathrm{C}_{\mathrm{V}}$ increases rapidly with the temperature upto $\mathrm{T} \approx 200 \mathrm{~K}$ for both the compounds (follows Debye $\mathrm{T}^{3}$ law) and at temperature, $\mathrm{T}>200, \mathrm{C}_{\mathrm{v}}$ approaches to a constant value (Dulong-Petit limit), indicating, temperature has high impact in temperature range $0<\mathrm{T}<200$ and small impact in temperature range, $\mathrm{T}>$
200. Fig. 10(c,d) indicate that pressure has opposite influence on the heat capacity and the effect of temperature on the heat capacity is more significant than that of pressure [19-21].

Fig. 11(a,b,c,d) show the variation of thermal expansion coefficient, $\alpha$ as a function of temperature and pressure. Fig. 11(a,b) show that the thermal expansion coefficient increases rapidly especially in the temperature range $0<\mathrm{T}<200 \mathrm{~K}$, whereas it gradually tends to increase at slow rate in higher temperature range $200<\mathrm{T}<300 \mathrm{~K}$. Fig. 11(c,d) show that $\alpha$ decreases with pressure at slow rate for $\mathrm{LaAuCd}$ whereas $\alpha$ decreases at faster rate within the pressure range 0-20 GPa and then decreases at slow rate in case of $\mathrm{La}_{2} \mathrm{Au}_{2} \mathrm{Cd}$, reflecting small impact of pressure on $\alpha$ for $\mathrm{LaAuCd}$ and high impact for $\mathrm{La}_{2} \mathrm{Au}_{2} \mathrm{Cd}$ [22].

Entropy is the measure of how much the energy of atoms and molecules become more spread out in a process. The variation of entropy, $\mathrm{S}$ in same temperature and pressure range for both the compounds has been shown in 12(a,b,c,d). Figs. 12(a,b) showed that at $0 \mathrm{~K}$, the entropy is zero for both the compounds and entropy increase rapidly as temperature increases. This increase in entropy with temperature is due to the increase of the vibrational motions of the atoms with temperature leading to the increase in the internal energy of the system. From Fig. $12(\mathrm{c}, \mathrm{d})$, it is observed that entropy decreases slowly with pressure. This is due to the fact that as pressure increases, the volume of unit cell decreases, results smaller space for energies 
of the particles. So they are less spread out and hence entropy decreases [23].

\section{Conclusion}

Full potential linearized potential augmented plane wave plus local orbital method along with generalized gradient approximation (GGA) has been applied to calculate the electronic structure and bonding properties whereas quasiharmonic Debye model has been used to study the thermodynamic properties of $\mathrm{LaAuCd}$ and $\mathrm{La}_{2} \mathrm{Au}_{2} \mathrm{Cd}$. Our calculated values of structural parameters are in good agreement with experimental/theoretical values. These lanthanum gold compounds possess the ionic metallic character. The band structure and density of states histograms show metallic character of both the compounds. Total density of states plots show that "La-p" and "Cd-d" orbital electrons have dominant character below the Fermi level whereas La-f orbitals are empty above the Fermi level for the conduction.

The bulk modulus, B decreases with increasing the temperature but increases with increasing the pressure, indicating degree of resistance of these compounds decreases with increasing the temperature but increases with increasing the pressure. The temperature has small impact on $\mathrm{B}, \theta_{\mathrm{D}}$ but high impact on $\mathrm{CV}$, $\alpha$ and $\mathrm{S}$ in temperature range $0<\mathrm{T}<300 \mathrm{~K}$. The pressure has high impact on $\mathrm{B}, \theta_{\mathrm{D}}$, but small impact on $\mathrm{C}_{\mathrm{V}}, \alpha$ and $\mathrm{S}$.

\section{REFERENCES}

1. P. Villars and L.D. Calvert, Pearson's Handbook of Crystallographic Data for Intermetallic Phases, American Society for Metals, Materials Park: Ohio, USA, edn 2 (1991).

2. R. Mishra, R. Pöttgen, R.-D. Hoffmann, D. Kaczorowski, H. Piotrowski, P. Mayer, C. Rosenhahn and B.D. Mosel, Z. Anorg. Allg. Chem., 627, 1283 (2001); https://doi.org/10.1002/1521-3749(200106)627:6<1283::AID-ZAAC1 $283>3.0 . \mathrm{CO} ; 2-\mathrm{L}$

3. J. Fickensc Rodewald, Ute C.; Niepmann, D.; Mishra, R.; Eschen, M.; Pöottgen, R., Z. Naturforsch, 60b, 271 (2005).

4. W. Rieger, H. Nowotny and F. Benesovsky, Monatsh. Chem., 95, 1502 (1964); https://doi.org/10.1007/BF00901704.
5. K. Remschnig, T. Le Bihan, H. Noël and P. Rogl, J. Solid State Chem., 97, 391 (1992); https://doi.org/10.1016/0022-4596(92)90048-Z.

6. R. Pöottgen, Z. Naturforsch. B, 49, 1309 (1994).

7. R. Pöottgen and R. Dronskowski, Z. Anorg. Allg. Chem., 622, 355 (1996); https://doi.org/10.1002/zaac.19966220225.

8. D. Laffargue, F. Fourgeot, F. Bouree, B. Chevalier, T. Roisnel and J. Etourneau, J. Solid State Commun., 100, 575 (1996); https://doi.org/10.1016/0038-1098(96)00475-9.

9. K. Schwarz and P. Blaha, Comput. Mater. Sci., 28, 259 (2003); https://doi.org/10.1016/S0927-0256(03)00112-5.

10. P. Blaha, K. Schwarg, G.K.H. Madsen, D. Kvasnicka and J. Luitz, WIEN2k, An Augmented Plane Wave Plus Local Orbitals Program for Calculating Crystal Properties, Technical University, Austria (2001).

11. G.K.H. Madsen, P. Blaha, K. Schwarz, E. Sjöstedt and L. Nordström, Phys. Rev. B, 64, 195134 (2001); https://doi.org/10.1103/PhysRevB.64.195134.

12. A. Otero-de-la-Roza, D. Abbasi-Pérez and V. Luaña, Comput. Phys. Commun., 182, 2232 (2011); https://doi.org/10.1016/j.cpc.2011.05.009.

13. F.D. Murnaghan, Proc. Natl. Acad. Sci. USA, 30, 244 (1944); https://doi.org/10.1073/pnas.30.9.244.

14. R.P. Singh, Indian J. Phys., 89, 377 (2015); https://doi.org/10.1007/s12648-014-0591-6.

15. R. Winter and J. Jonas, High Pressure Chemistry, Biochemistry and Material Science, Springer Science and Business Media, B.V. (1992).

16. B.D. Fahlman, Materials Chemistry, Springer, Dordrecht (2011).

17. U. Benedict and W.B. Holzapfel, ed.: K.A. Gschneidner, High Pressure Studies-Structural Aspects, In: Handbook of Physics and Chemistry of Rare Earths, North Holand, Amsterdam (1993).

18. S. Stolen and T. Grande, Chemical Thermodynamics of Materials: Macroscopic and Microscopic Aspects, Wiley (2004).

19. D. McQuarrie, Quantum Chemistry, University Science Books: USA, edn 2 (2008).

20. G.N. Lewis, J. Am. Chem. Soc., 29, 1165 (1907); https://doi.org/10.1021/ja01962a002.

21. P.J. van der Put, The Inorganic Chemistry of Materials: How to Make Things out of Elements, Plenum Press: New York (1998).

22. C.Y. Ho and R.E. Taylor, Thermal Expansion of Solids edited by CINDAS Data Series on Material Properties, I-4 (1998).

23. N. Shulumba, Ph.D. Thesis, Vibrations in Solids: From First Principles Lattice Dynamics to High Temperature Phase Stability Nanostructured Materials, Department of Physics, Chemistry and Biology, Linköping University, Sweden (2015). 